\title{
Penerapan Aplikasi Inventory Barang dengan Menggunakan Extreme Programming Pada Perusahaan Manufaktur
}

\author{
Julia Loisa ${ }^{1)}$ Titus Zefanya Ivgantius ${ }^{2)}$ Johanes Fernandes Andry ${ }^{3)}$ \\ 1,2,3) Sistem Informasi, Fakultas Teknologi dan Desain, Universitas Bunda Mulia \\ Jalan Lodan Raya No.2, Ancol, Jakarta 14430 \\ ${ }^{1}$ Email: jloisa@bundamulia.ac.id, ${ }^{2)}$ zivgantius@gmail.com, ${ }^{3)} j a n d r y @ b u n d a m u l i a . a c . i^{d}$
}

\begin{abstract}
Today's technology continues to grow rapidly because of the function of the technology itself that can help users manage a data faster. Thus the application of a system becomes a natural thing if the company wants to increase sales of products it has created. Manufacture Company is a company that produces liquid fertilizer which is then sold to consumers. But in terms of recording the availability of goods as well as recording sales transactions are still done manually, it will eventually affect the company because of the increasing market demand. Therefore an inventory application system was built to accommodate this. This application is designed with the main goal of making it easier for workers to record the availability of goods and sales transactions to be more systematic. This application will be created using Visual Basic programming language and has a database server, MySQL. The method used to design this application uses SDLC Extreme Programming. This application is expected to be able to simplify the process of recording an item, both material received from suppliers and the results of production, as well as produce a better sales report than previously done manually.
\end{abstract}

Keywords: inventory application, SDLC Extreme Programming, Visual Basic

\begin{abstract}
Abstrak: Teknologi sekarang ini terus berkembang pesat dikarenakan fungsi dari teknologi itu sendiri yang dapat membantu penggunanya mengelola suatu data menjadi lebih cepat. Dengan demikian penerapan suatu sistem menjadi suatu hal yang wajar apabila perusahaan ingin meningkatkan penjualan produk yang telah diciptakannya. Perusahaan manufaktur merupakan suatu perusahaan yang memproduksi pupuk cair yang kemudian dijual kepada para konsumen. Namun dalam hal pencatatan ketersediaan barang serta pencatatan transaksi penjualan masih dilakukan secara manual, hal tersebut lama-kelamaan berpengaruh terhadap perusahaan karena permintaan pasar yang terus meningkat. Oleh karena itu dibangun sebuah sistem aplikasi inventory untuk mengakomodasi hal tersebut. aplikasi ini dirancang dengan tujuan utama yaitu memudahkan pekerja dalam mencatat segala ketersediaan barang dan transaksi penjualan agar menjadi lebih sistematis. Aplikasi ini akan dibuat menggunakan bahasa pemprograman visual basic serta memiliki database server yaitu MySQL. Metode yang digunakan untuk merancang aplikasi ini menggunakan SDLC Extreme Programming. aplikasi ini diharapkan mampu mempermudah dalam proses pencatatan suatu barang, baik bahan yang diterima dari pemasok maupun hasil produksi, serta menghasilkan suatu laporan hasil penjualan yang lebih baik dibandingkan sebelumnya yang dilakukan secara manual.
\end{abstract}

Kata kunci: aplikasi inventory, SDLC Extreme Programming, Visual Basic

\section{PENDAHULUAN}

Perusahaan manufaktur merupakan salah satu perusahaan yang memproduksi pupuk hayati cair yang di jual kepada para petani dan masyarakat di daerah Timur dan di wilayah Indonesia. Sebagai suatu perusahaan yang memiliki visi dan misi, tentunya juga memiliki suatu tujuan yang dijalankan untuk mendukung kegiatan-kegiatan operasional yang ada [1]. Walaupun demikian untuk dapat mencapai hal tersebut dibutuhkan suatu penerapan sistem informasi agar dapat membantu perusahaan dalam pengambilan keputusan manajemen dan memberikan informasi yang layak bagi perusahaan [2] Selain itu dengan adanya sistem informasi juga dapat membantu mengurangi terjadinya suatu kesalahan yang tidak diinginkan sehingga dapat meningkatkan kinerja yang akurat [3], [4]

Sistem informasi sendiri merupakan kumpulan elemen yang saling berhubungan dan berfungsi untuk 
memproses, mengumpulkan, mendistribusikan, serta menyimpan informasi yang berguna sebagai pendukung dalam pembuatan keputusan juga pengawasan dalam organisasi yang bersifat manajerial dengan kegiatan strategi dari suatu organisasi [5], [6].

Sistem informasi yang memiliki keterkaitan antara komponen dalam mengumpulkan, memproses, menyimpan, dan memberikan informasi keluaran yang dibutuhkan untuk menyelesaikan tugas-tugas yang berhubungan dengan bisnis [7], [8]. Namun pada penerapan sistem informasi pada perusahaan manufaktur dapat dikatakan cukup kompleks dan kurang terintegrasi dengan sistem sehingga segala aktivitas yang berhubungan dengan pencatatan dilakukan secara manual seperti penyimpanan barang di gudang dan bukti penjualan setiap harinya. Dengan demikian pencatatan secara komputerisasi diperlukan agar dapat mengurangi kesalahan-kesalahan yang biasa terjadi pada saat masih melakukan input data barang secara manual [9].

Aplikasi inventory merupakan salah satu solusi yang ditawarkan untuk membantu perusahaan dalam mendokumentasikan data-data yang berhubungan dengan ketersediaan barang dan penjualan kepada pembeli [10]. Kemudian dalam penyusunan suatu aplikasi inventory dibutuhkan suatu metode pengembangan sistem SDLC (System Development Life Cycle) yaitu Extreme Programming.

Extreme Programming (XP) merupakan salah satu metode pengembangan perangkat lunak yang paling banyak digunakan dan menjadi pendekatan yang sangat terkenal. Tahapan yang dilakukan dalam metode ini meliputi planning, design, coding, dan testing [11].

Dalam pembuatan aplikasi inventory Extreme Programming dipilih sebagai metode yang tepat terhadap perubahan yang akan muncul selama aplikasi dikembangkan. Oleh karena itu, maka peneliti menyimpulkan untuk melakukan pembuatan sebuah perancangan sistem inventory untuk dapat memenuhi kebutuhan yang ada pada perusahaan manufaktur.

\section{METODE PENELITIAN}

Extreme Programming adalah model SDLC yang termasuk dalam metode agile yang diperkenalkan oleh Kent Beck. Menurut Kent Beck "Extreme Programming (XP) adalah pengembangan perangkat lunak yang cepat, efisien, berisiko rendah, fleksibel, dapat diprediksi, ilmiah, dan menyenangkan". Dalam pengembangan perangkat lunak terdapat empat fase utama yaitu planning, coding, designing, dan testing [12].

Pada Gambar 1 model extreme programming terdapat proses dan tahapan yaitu:
1. Perencanaan (Planning). Kegiatan perencanaan (disebut juga planning game) biasanya dimulai dengan mendengarkan suatu kegiatan yang bertujuan untuk mengumpulkan kebutuhan kebutuhan yang memungkinkan anggota teknis tim XP memahami konteks bisnis untuk perangkat lunak yang akan dikembangkan. Dalam pembangunan aplikasi inventory pada tahapan ini dimulai dari mengindetifikasi permasalahan yang timbul pada sistem yang sedang berjalan. Kemudian melakukan analisa kebutuhan pengguna terhadap sistem yang akan dibangun.

2. Perancangan (Design). Pada tahapan perancangan dilakukan pembuatan pemodelan suatu sistem berdasarkan hasil analisa kebutuhan yang didapatkan. Pemodelan sistem yang digunakan yaitu Unified Modeling Language (UML) yang terdiri dari Use case Diagram, activity Diagram serta Class Diagram.

3. Pengkodean (Coding). Tahapan ini merupakan implementasi dari perancangan model sistem yang telah dibuat ke dalam kode pemprograman yang menghasilkan sebuah prototype dari perangkat lunak. Dalam pembangunan aplikasi inventory menggunakan bahasa pempro-graman VB.Net. Sedangkan untuk implementasi basis data, Database Management System adalah MySQL.

4. Pengujian (Testing). Tahapan ini merupakan tahapan pengujian terhadap aplikasi yang sudah dibuat. Aplikasi tersebut kemudian akan ditinjau oleh pengguna sistem mengenai keseluruhan fitur dan fungsionalitas dari sistem itu sendiri [14], [15].

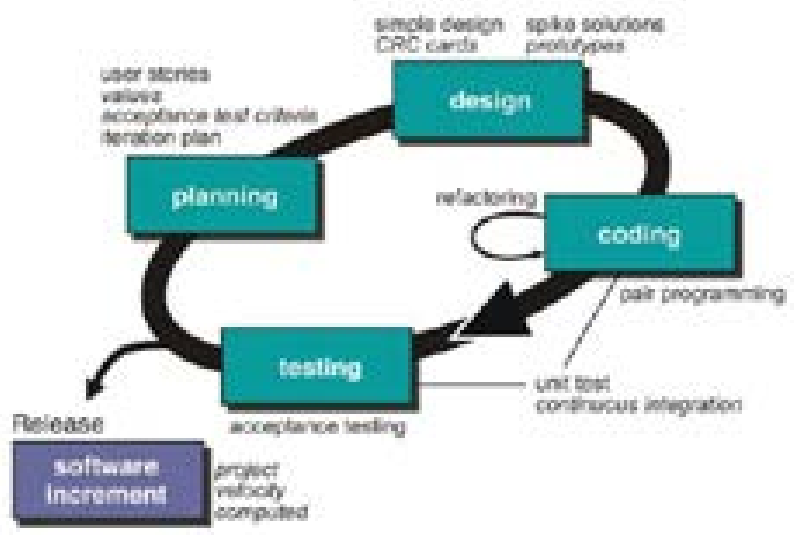

Gambar 1. Model Extreme Programming [12], [13].

\section{HASIL DAN PEMBAHASAN}

\section{A. Perencanaan}

1. Identifikasi Permasalahan. Pemasalahan yang timbul saat ini adalah belum adanya sistem yang dapat digunakan untuk mencatat persediaan barang serta penjualan kepada pembeli sehingga masih dilakukan secara manual yaitu menggunakan kertas 
yang menyebabkan proses pencatatan memakan waktu lebih lama. Selain itu proses keluar masuk barang menjadi tidak tercatat dengan baik sehingga data stok tidak selalu update.

2. Analisa Kebutuhan. Pada tahapan ini pihak yang dapat melakukan akses untuk menggunakan aplikasi terdapat dua aktor yaitu admin dan operator. Admin dapat mendaftarkan atau membuat akun yang akan digunakan untuk operator melakukan login di dalam aplikasi tersebut. Sedangkan operator memiliki aktivitas melakukan penginputan barang yang di dapat dari supplier serta mencatatnya di dalam sistem.

\section{B. Perancangan}

\section{Use Case Diagram}

Pada Gambar 2 use case diagram inventory mengGambarkan mengenai hubungan antara aktor dengan aktivitas yang ada pada sistem yang terdiri dari admin dan operator.

Pada aktor admin memiliki wewenang paling tinggi dibandingkan aktor lainnya, admin dapat melakukan pembuatan akun yang nantinya akan digunakan oleh operator sebagai syarat untuk login, kemudian admin juga dapat memasukan input baru data barang yang nanti nya hasil inputan tersebut akan digunakan oleh operator untuk memasukkan jumlah barang yang berkurang dan bertambah.

Pada saat akun operator login, dapat mengelola data atau bahan mentah yang didapat dari pemasok atau supplier pada saat pemesanan, kemudian operator juga dapat melakukan retur barang kepada supplier atau pemasok jika barang yang diterima mengalami kerusakan sebelum digunakan oleh pekerja.

\section{Activity Diagram}

Pada Gambar 3 Activity Diagram Inventory

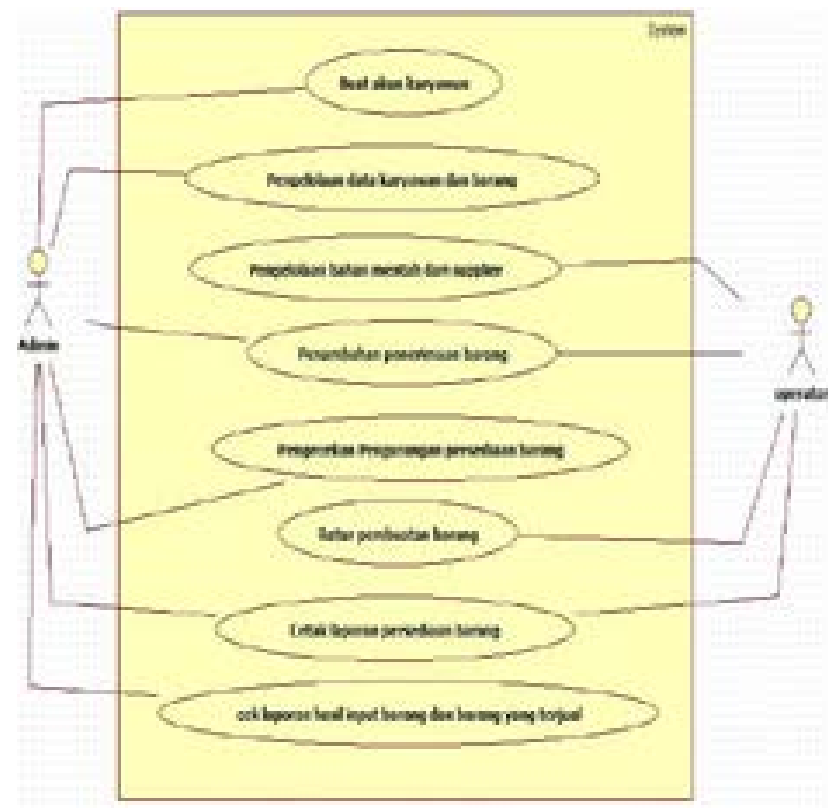

Gambar 2. Use Case Diagram Inventory menjelaskan mengenai aktivitas pada masing-masing peran yang terdiri atas aktor admin dan operator.

Pada aktor admin, dapat membuat akun baru untuk pihak operator yang memiliki hak atas pernggunaan aplikasi inventory kemudian setelah admin memberikan akun baru tersebut kepada operator, pekerja tersebut dapat langsung login dan melakukan aktivitas yang diperlukan oleh selama kegiatan produksi berlangsung.

Setelah admin selesai membuat data-data bahan yang diperlukan untuk keperluan produksi, maka operator dapat langsung melihat bahan-bahan yang dibutuhkan selama proses produksi berlangsung untuk di data ke dalam sistem.

Selain itu, operator juga menginputkan bahan yang masuk atau datang dari pemasok, hal tersebut berguna untuk mengetahui berapa banyak jumlah bahan yang dipesan dan diterima di tempat produksi. Pada proses sebelum penginputan bahan yang masuk, operator melakukan pengecekan terlebih dahulu seputar bahan yang diterima, apabila bahan mengalami kerusakan makan akan langsung dikembalikan kepada pemasok. Setiap bahan yang dikembalikan didata di dalam sistem untuk mengetahui berapa banyak bahan yang di-retur kepada pemasok.

Apabila hal tersebut sudah dilakukan, operator dapat membuat sejumlah laporan yang nanti nya akan diserahkan kepada admin sebagai bukti pemesanan bahan material yang dipesan dari pemasok. Pada Gambar 5 Tampilan form login dan pada Gambar 6 . Tampilan home, diperlihatkan adalah tampilannya pada aplikasi tsb.

Pada Gambar 4 Class Diagram Inventory terdapat beberapa kelas serta atribut yang digunakan dalam perancangan sistem aplikasi inventory.

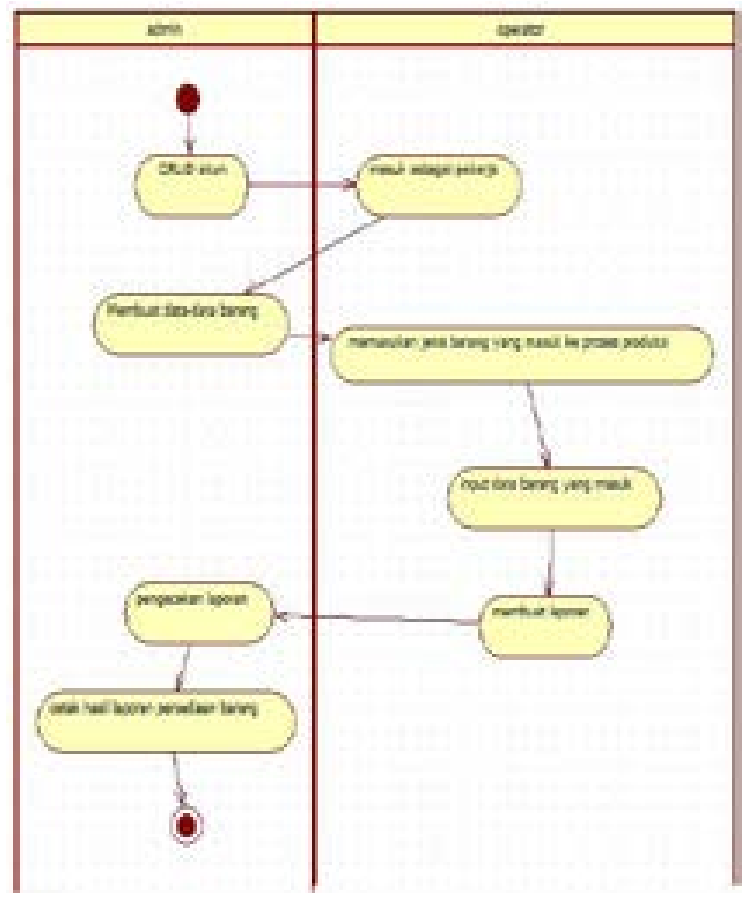

Gambar 3. Activity Diagram Inventory 


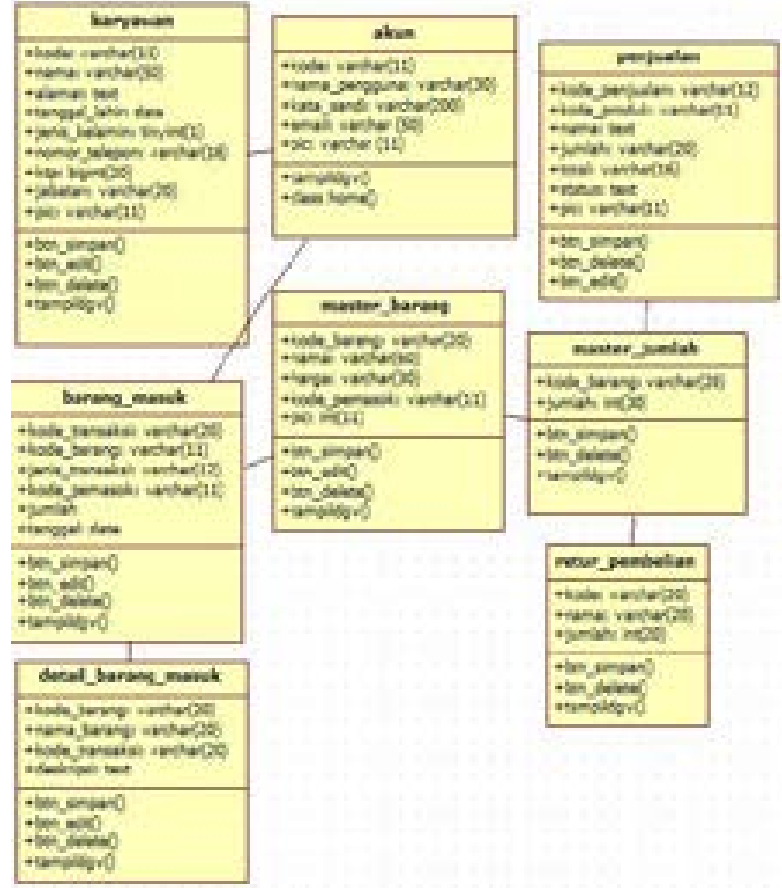

Gambar 4. Class Diagram Inventory

\section{Pengkodean}

Pada tahapan ini, menjelaskan mengenai beberapa tampilan design aplikasi yang telah dibuat. Perancangan sistem informasi inventory ini menggunakan bahasa pemprograman visual basic 2013 serta menggunakan basis data MySQL sebagai tempat menyimpan data-data yang telah diinputkan oleh pekerja. seperti Gambar 5 dan Gambar 6.

\section{Pengujian}

Pada tahapan ini merupakan langkah yang dapat dilakukan untuk mengetahui apakah sistem yang telah

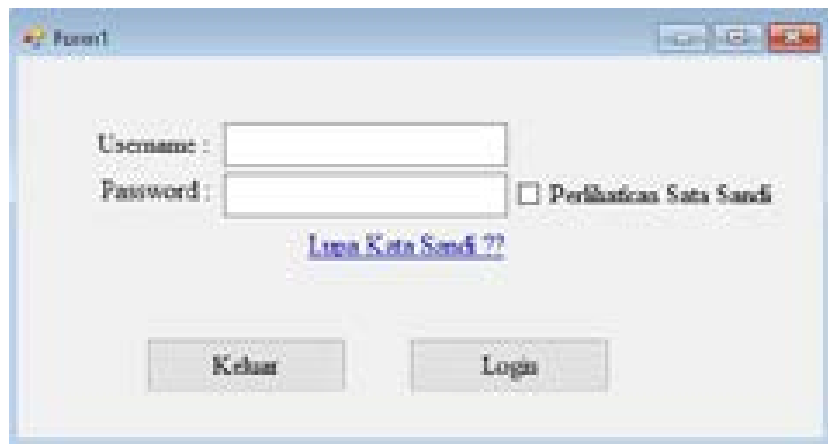

Gambar 5. Tampilan form login

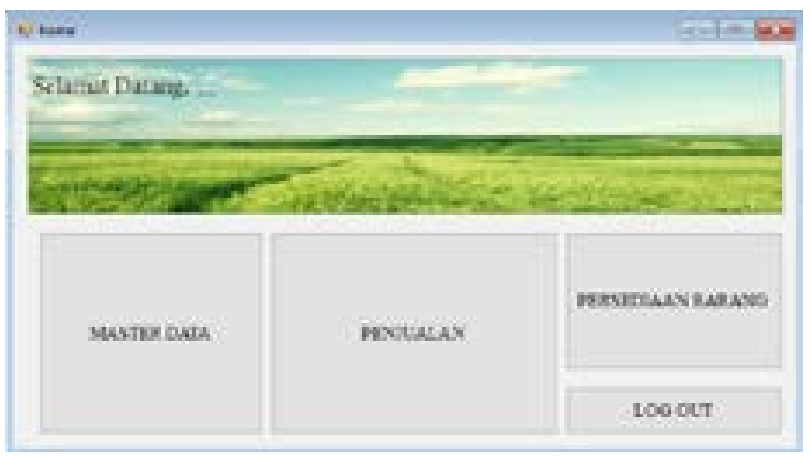

Gambar 6. Tampilan home

dibuat mengalami error atau bugs yang kemungkinan akan muncul di dalam aplikasi. Proses ini memiliki peranan penting sebagai pengguna akhir untuk pengecekan semua fitur aplikasi bekerja dengan benar. Penguji melakukan pengecekan secara manual tanpa menggunakan bantual dari tools atau scripts, tujuannya adalah untuk memastikan jika aplikasi yang di uji bebas cacat dan aplikasi perangkat lunak dapat bekerja sesuai dengan apa yang diharapkan. Untuk hasil dari pengetesan dapat dilihat pada Tabel 1 module tampilan form login.

Tabel 1. Module Tampilan Form Login

\begin{tabular}{|c|c|c|c|c|}
\hline No. & Test Case & Test Steps & Expected Result & Actual Result \\
\hline 1. & $\begin{array}{l}\text { Tampilan login muncul } \\
\text { setelah aplikasi } \\
\text { dijalankan }\end{array}$ & $\begin{array}{l}\text { masukkan teks pada textbox } \\
\text { 1.'abcde; atau 'ABCDE' } \\
\text { (tanpa kutip) } \\
\text { 2. } 0123 \\
456789 \\
\text { 3. '!@\#\$\%^\&*()_+- } \\
=\{[\}] \mid \wedge: "{ }^{+}<,>\text {? } /(\text { dan spasi) }\end{array}$ & $\begin{array}{l}\text { Berhasil menampilkna } \\
\text { huruf kapital, angka, dan } \\
\text { simbol ke textbox } \\
\text { username. }\end{array}$ & $\begin{array}{l}\text { Pengguna dapat } \\
\text { memasukkan huruf } \\
\text { kapital, angka, dan } \\
\text { simbol ke dalam } \\
\text { textbox username. }\end{array}$ \\
\hline 2. & $\begin{array}{l}\text { Tampilan login muncul } \\
\text { setelah aplikasi } \\
\text { dijalankan dengan } \\
\text { username 'admin' dan } \\
\text { password 'admin' yang } \\
\text { telah didaftarkan di } \\
\text { dalam sistem. }\end{array}$ & $\begin{array}{l}\text { 1.masukkan nama 'admin' } \\
\text { ke textbox username. } \\
\text { 2.kosongkan textbox } \\
\text { password. } \\
\text { 3.klik tombol login. }\end{array}$ & $\begin{array}{l}\text { Akan menampilkan pesan } \\
\text { data tidak lengkap. }\end{array}$ & $\begin{array}{l}\text { Berhasil } \\
\text { menampilkan pesan } \\
\text { data tidak lengkap. }\end{array}$ \\
\hline 3. & $\begin{array}{l}\text { Tampilan login muncul } \\
\text { setelah aplikasi } \\
\text { dijalankan dengan } \\
\text { username 'admin' } \\
\text { Dan password } \\
\text { 'ADMIN' } \\
\end{array}$ & $\begin{array}{l}\text { 1. masukkan nama 'admin' } \\
\text { pada textbox username. } \\
\text { 2. masukkan password } \\
\text { 'ADMIN' } \\
\text { 3. klik tombol 'login' }\end{array}$ & $\begin{array}{l}\text { Akan menampilkan pesan } \\
\text { password yang anda } \\
\text { masukkan salah. }\end{array}$ & $\begin{array}{l}\text { Berhasil } \\
\text { menampilkan } \\
\text { password yang anda } \\
\text { masukkan salah. }\end{array}$ \\
\hline 4. & $\begin{array}{l}\text { Admin keluar dari } \\
\text { aplikasi saat menekan } \\
\text { tombol keluar pada } \\
\text { halama login }\end{array}$ & $\begin{array}{l}\text { 1. menekan tombol 'keluar' } \\
\text { pada halaman login. }\end{array}$ & $\begin{array}{l}\text { Berhasil keluar dari } \\
\text { halaman login }\end{array}$ & $\begin{array}{l}\text { Keluar dari aplikasi } \\
\text { inventory. }\end{array}$ \\
\hline
\end{tabular}




\section{SIMPULAN}

Berdasarkan hasil kajian perancangan sistem informasi aplikasi inventory sangat memberikan kemudahan kepada pekerja terutama pada saat proses pendataan persediaan barang, baik barang masuk maupun barang keluar serta pembuatan laporan pembelian bahan material dari supplier yang kini dapat langsung di cetak melalui sistem yang telah disediakan. Selain itu aplikasi ini juga mampu menghasilkan informasi yang tepat kepada penggunanya dalam mengetahui berapa jumlah stok barang yang tersedia didalam tempat penyimpanan.

\section{DAFTAR PUSTAKA}

[1] A. T. Helmi., I. Aknuranda., dan M. C. Saputra. M. C. Analisis Dan Pemodelan Proses Bisnis Menggunakan Business Process Improvement (BPI) Pada Lembaga Bimbingan Belajar (Studi Kasus : Lembaga Bimbingan Belajar Prisma). Vol. 2, No. 10, 2018.

Link: http:/j-ptiik.ub.ac.id/index.php/j-ptiik/article/ view/2868

[2] A. F. Pamungkas., N. H. Wardani. dan M. C. Saputra. Pengembangan Sistem Informasi Persediaan Barang , Harga Pokok Produksi, dan Transaksi Penjualan Berbasis Web (Studi Pada Son Screen Printing Sidoarjo). Vol. 2, No. 6, hlm. 2075-2084. 2018. Link: http://j-ptiik.ub.ac.id/index.php/j-ptiik/article/ view/1601

[3] S. Santoso., T. Maryani. dan D. P. Rosmana. Perancangan Sistem Informasi Persediaan Barang untuk Mengetahui Jumlah Stok Barang pada Warehouse Fitting PT . Suryo Toto. Vol. 1, hlm. 149-158. 2017. Link: https://doi.org/10.21776/ ub.industria.2019.008.02.5

[4] S. Ramadina., dan S. Hadi. Pengembangan Sistem Informasi Manajemen Bengkel Kerja Sekolah Menengah Kejuruan. Vol. 5, No. 1, hlm. 103-116. 2015. Link: https://journal.uny.ac.id/index.php/jpv/ article/view/6078

[5] A. Anthony., A. R. Tanaamah., dan A. F. Wijaya. Analisis dan Perancangan Sistem Informasi Penjualan Berdasarkan Stok Gudang Berbasis Client Server (Studi Kasus Toko Grosir 'Restu Anda'). Vol. 4, No. 2, hlm. 136-147. 2017.
[6] D. Anggraeni. Sistem Informasi Tata Kelola Pendaftaran Kontrak Cafetaria dan Restoran PT. Angkasa Pura II Bandara Minang Kabau. JURTEKSI( J. Teknol. dan Sist. Informasi), vol. 5, no. 1, hlm. 43$50,2018$.

[7] K. Anam., dan A. T. Muharram. Analisa dan Perancangan Sistem Informasi Akademik Berbasis Web pada MI Al-Mursyidiyyah Al-'Asyirotussyafi'yyah. Vol. 11, No. 2, hlm. 207-217. 2018. Link: http://dx.doi. org/10.15408/jti.v11i2.8867

[8] Y. Pernando., E. L. Febrianti., dan Andhika. Analisa dan Perancangan Sistem Informasi Pasien Rawat Inap (Studi Kasus: Rumah Bersalin Azimar Anas Padang). Vol. V, No. 2, hlm. 139-146. 2019. Link: DOI: https:// doi.org/10.33330/jurteksi.v5i2.358

[9] M. B. Rahmad., dan T. Setiady. Perancangan Sistem Informasi Inventory Spare Part Elektronik Berbasis Web PHP (Studi CV. Human Global Service Yogyakarta). Vol. 2, hlm. 256-265, 2014.

[10] B. U. Fahnun., H. D. Hartono. Dan Y. Karyanti. Perancangan Sistem Inventory Berbasis Web (Studi Kasus PT . Continental Panjipratama). Vol. 6, No. 1, hlm. 8-14. 2014.

[11] Purmasari. Development of Information Systems Using Extreme Programming Method. Vol. 3, No. 2, hlm. 9599. 2018. Link: https://ejournal.unitomo.ac.id/index. php/inform/issue/view/80

[12] J. F. Andry., G. Juliawan., Y. Christian., dan J. Leonardo. Parking System Development Using Extreme Programming Method. Vol. 16, No. 6, hlm. 279-288. 2019. Link: DOI: 10.6025/jdim/2018/16/6/279-288.

[13] B. G. Sudarsono., s. P. Lestari., A. U. Bani., J. Chandra dan J. F. Andry. Using an Extreme Programming Method for Hotel Reservation System Development. International Journal of Emerging Trends in Engineering Research. Vol. 8, no.6, hlm 2223-2228. 2020.

[14] J. F. Andry., H. Tannady., dan F. E. Gunawan. Purchase Order Information System using Feature Driven Development Methodology. International Journal of Advanced Trends in Computer Science and Engineering. Vol. 9, no.2, hlm 1107-1112. 2020.

[15] J. F. Andry., j. S. Suroso., dan D. Y. Bernanda. Improving Quality Of SMEs Information System Solution With ISO 9126. Journal of Theoretical and Applied Information Technology. Vol. 96. No. 14. hlm 4610-4620. 2018. 